\title{
Birth control "debacle" prompts calls for swifter public notices
}

$\mathrm{T}$ wo major health organizations are urging Health Canada to inform the public immediately when it learns of problems that reduce the efficacy of contraceptives, following what they call the "Alysena 28 faulty birth control debacle."

Since early April, Alysena 28, a birth control pill distributed by Apotex Canada, has been subjected to a series of recalls due to a packaging flaw that could put thousands of women at risk of pregnancy. Alysena 28 is supposed to contain three rows of seven active pills (pink) and one row of seven placebo pills (white). The pills were recalled because of an error that put 14 active pills and 14 placebo pills in a pack, instead of 21 active pills and seven placebos, in at least one lot.

"It is a totally unprecedented event that we should have a breach of this nature in contraceptive medication," says Dr. Jennifer Blake, chief executive officer of the Society of Obstetricians and Gynaecologists of Canada (SOGC).

"We don't know yet what the longterm effects will be, not only in terms of unwanted pregnancies, but also in a loss of confidence" among women using contraceptives, she adds.

The SOGC and the College of Family Physicians of Canada (CFPC) issued a joint statement Apr. 24 criticizing Health Canada's initial response to accept the manufacturer's voluntary recall of the pills without notifying the public. They also made a series of recommendations to prevent future mishaps.

The Society of Gynaecologists and Obstetricians' recommendations refer specifically to contraceptives, but are overarching, Blake told CMAJ.

"The contraceptive debacle has brought the need sharply into focus, but I think what's good for contraception is good for other drugs," she says.

Becoming pregnant unexpectedly is reason enough for concern, but pregnancy becomes a health risk for some

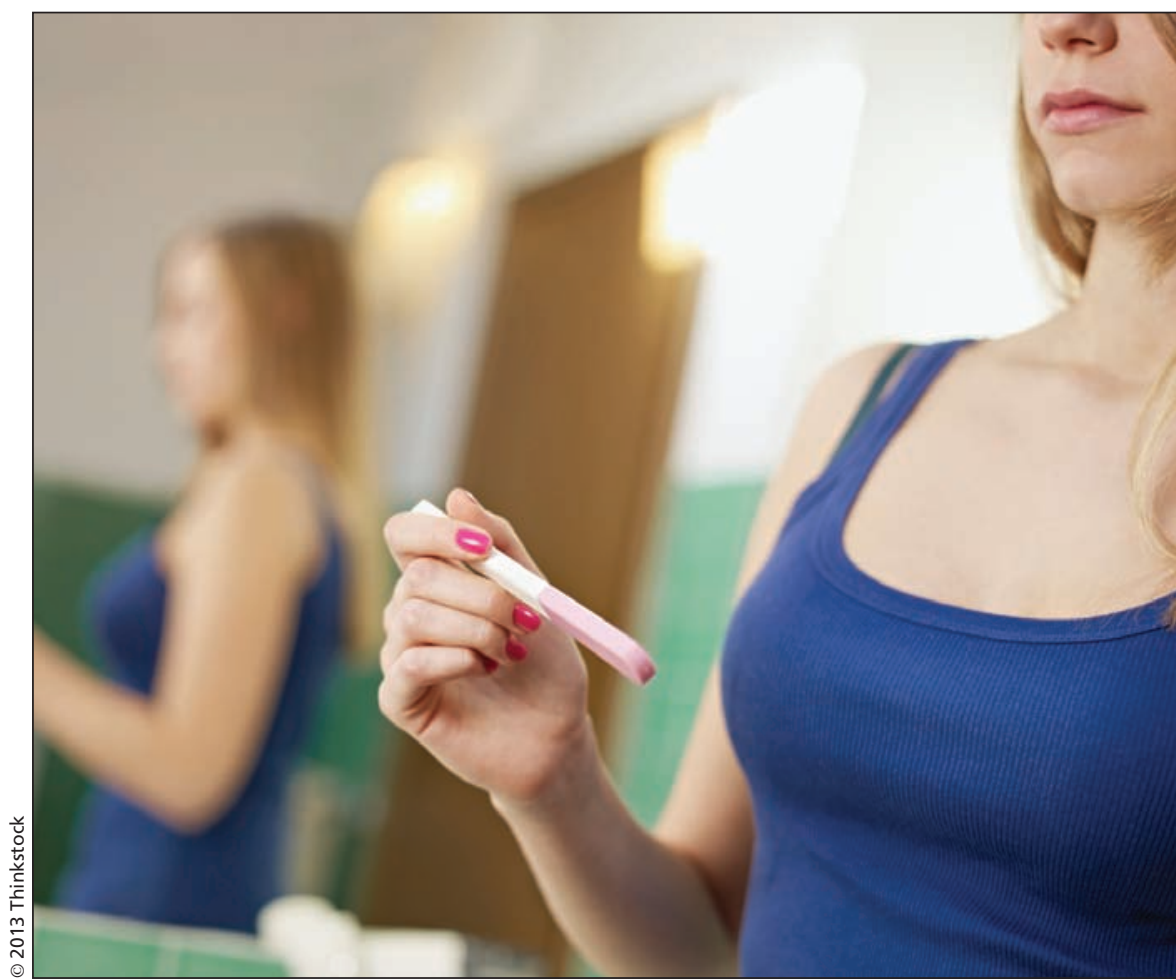

A packaging error that replaced a week of active birth control pills with placebos in an Apotex Canada product put sexually active women at the same risk of becoming pregnant as if they were not using contraception at all, according to an Apotex public advisory.

women taking contraindicated medications or with certain medical conditions. Health Canada should also require pharmacies to tell patients and doctors when they substitute generic brands for name-brand drugs, the health care organizations say, because some women may not know they are taking Alysena.

Alysena is the generic version of Alesse, a contraceptive made by Pfizer. Many pharmacies fill Alesse prescriptions with Alysena in order to meet drugplan requirements to save money, and the similar names can cause confusion.

The Alysena recall began Apr. 3, when Apotex issued a Type II voluntary recall of one lot of Alysena 28 from all wholesalers, retailers and distributors. The Type II recall took the pills off shelves but did not require retailers to inform patients who might have received faulty drugs.

Five days after the first recall, Health Canada issued a Type I voluntary recall, requiring retailers to contact women who bought the pill. This level of recall is Health Canada's most urgent health-hazard classification. It is used in "a situation in which there is a reasonable probability that the use of, or exposure to, a product will cause serious adverse health consequences or death," the department's policy describes.

On Apr. 12, Apotex recalled an additional 11 lots of Alysena 28. Three days later, it recalled all lots of Alysena 28. The additional recalls are precautionary while Apotex investigates what it calls a "packaging error" in the original lot, although there is no evidence so far that 
other lots were affected, the company said in a news release. Missing a week of pink pills puts sexually active women at the same risk of becoming pregnant as if they were not using contraception, Apotex's public advisory warns.

Apotex declined to respond to any further questions, directing $C M A J$ to its release.

Health Canada says it was Apotex's responsibility to notify Alysena 28's distributors and users about the recall.

"When health product recalls do occur, the primary role of Health Canada is to closely monitor the effectiveness of the company's recall actions and to provide scientific, technical and operational advice," the department wrote in an email to CMAJ.

Health Canada says it upgraded the recall to Type I as soon as it realized the error might jeopardize some women's health. The department also added recall information to its Healthy Canadians database and tweeted a link to the information.

This recall should be "a learning experience for everyone," says Phil Emberley, director of pharmacy innovation for the Canadian Pharmacists Association.

"I can't say how early on Health
Canada got information from [Apotex]. My concern is primarily around the classification of the hazard to Canadians," he says. "It should have been assessed stronger early on. The Canadian public expects more."

The recall damages Canadians' confidence in drug regulation and brings attention to gaps that exist in drug industry oversight, says Anne Rochon Ford, executive director of Canadian Women's Health Network. "It puts women at risk, but also in a state of worry and fear." Catherine Cross, CMAJ

CMAJ 2013. DOI:10.1503/cmaj.109-4481 